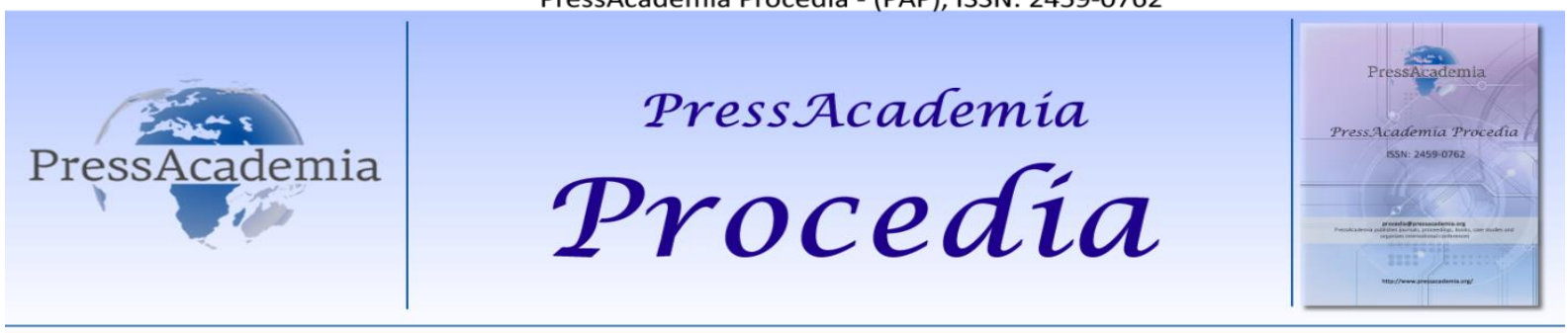

Global Business Research Congress (GBRC), May 24-25, 2017, Istanbul, Turkey

\title{
THE UNIVERSITY STUDENTS' SOCIAL MEDIA USAGE HABITS AND THEIR PERCPECTIVES OF ENTREPRENEURIAL ACTIVITIES VIA INTERNET, SAMPLE OF SELCUK UNIVERSITY BEYSEHIR ALI AKKANAT CAMPUS
}

DOI: 10.17261/Pressacademia.2017.634

PAP-GBRC-V.3-2017(60)-p.597-60

Emine Vasfiye Korkmaz ${ }^{1}$, Yasar Korkmaz ${ }^{2}$

${ }^{1}$ Selçuk Ünviversitesi. eminekorkmaz@selcuk.edu.tr

${ }^{2}$ Kahramanmaraş Sütçü İmam Üniversitesi, ykorkmaz46@ksu.edu.tr

To cite this document

Korkmaz, E. and Y.Korkmaz (2017). The university students' social media usage habits and their percpectives of entrepreneurial activities via internet, sample of Selcuk University Beysehir Ali Akkanat. PressAcademia Procedia (PAP), V.3, p.597-604.

Permemant link to this document: http://doi.org/10.17261/Pressacademia.2017.635

Copyright: Published by PressAcademia and limited licenced re-use rights only.

\begin{abstract}
The aim of this study is to evaluate the interaction of the university students 'social media usage habits and their percpectives of Entrepreneurial activities via internet. In the study, survey technique is used as data collecting instrument. In the context of this study, we administered a structured survey to students in Selçuk University Beyşehir Ali Akkanat Campus. The data obtained in this study will be analyzed by the programme of SPSS23. It is considered that the findings to be obtained at the end of the study will make contribution to eliminating the deficiency in the area and will present useful opinions toward the literature and application.
\end{abstract}

Keywords: Social media, internet, entrepreneurial activities, business, students

JEL Codes: M10, M12, M15

\section{ÜNIVERSiTE ÖĞRENCILERININ SOSYAL MEDYA ALIŞKANLIKLARI VE INTERNET ÜZERINDEN GiRişiMciLiK FAALIYETLERINE BAKIŞ AÇILARI, SELÇUK ÜNIVERSitESi BEYŞEHIR ALI AKKANAT KAMPÜSÜ ÖRNEĞi}

\section{ÖZET}

Bu çalışmanın amacı üniversite öğrencilerinin sosyal medya alışkanlıkları ve internet üzerinden girişimcilik faaliyetlerine bakış açılarını değerlendirmektir. Araştırmada veri toplama aracı olarak anket tekniği kullanılmaktadır. Araştırma kapsamında Selçuk Üniversitesi Beyşehir Ali Akkanat Kampüsündeki öğrencilere anket uygulanmıştır. Bu çalışmada elde edilen veriler SPSS20 programı ile analiz edilecektir. Çalışma sonucunda elde edilecek bulguların alandaki eksikliğin giderilmesine katkı sağlayacağı, yazına ve pratik uygulamaya yönelik yararlı fikirler sunacağı düşünülmektedir

Anahtar Kelimeler: Sosyal medya, internet, girişimcilik faaliyetleri, işletme, öğrenciler JEL Kodları: M10, M12, M15 


\section{GíRiş}

Sosyal medya çok hızlı bir şekilde büyümekte ve hızla farklı farklı sektörlerde ciddi bir öneme sahip olmaktadır. Sosyal medyanın hızla büyüyen bu gücü girişimciler için de önemli bir stratejik hamle haline gelmiştir. İnternet ve sosyal medya üzerine yapılan araştırmaların çoğu göstermektedir ki öğrenciler günlerinin büyük bir saat dilimini sosyal medya ile meşgul olarak geçirmektedirler. Müzik, oyun, sosyal ağlar gibi internet ve sosyal medya üzerinden alışverişin de öğrenciler açısından önemli olduğu araştırma sonuçlarında gözlemlenmektedir. Bu çalışmanın amacı üniversite öğrencilerinin sosyal medya üzerinden girişimciliğe bakış açılarını değerlendirmektir.

\section{LITERATUR INCELEMESI}

\subsection{Girişimcilik ve Sosyal Medya}

Illk kez 18. Yüzyılın başında Fransız ekonomist Richard Cantillon tarafından; "henüz belirginleşmemiş bir bedelle satmak üzere üretim girdilerini ve hizmetlerini bugünden satın alan ve üreten kişi” olarak tanımlanan girişimcinin günümüzde çok çeşitli tanımlamaları yapılmaktadır (Aktaran: Çelik ve Akgemci, 2010:15). Girişimcilik, girişim faaliyeti sonucunda bireysel bağımsızlık, tatmin, haz gibi psikolojik, para, servet, gelir gibi ödül olan ekonomik, statü, itibar, güç gibi sosyolojik sonuçlara yol açan, tehlike, tuzak, streslerle dolu ve özel gayret gerektiren bir değer yaratma sürecidir (Aktaran: Karaca, 2015:29). Benzer bir tanıma göre ise girişimcilik, pazardaki niş noktaları fark etmek, bu noktalardaki fırsatları görmek ve uygun projelerle değerlendirmektir. Daha genel ve kapsayıcı bir tanıma göre de girişimcilik, sorun/ihtiyaç ve fırsatları görmek, fırsatlardan faydalanmak ya da sorun ve ihtiyaçlara çözüm üretmek amacıyla ürün/hizmet ya da toplumsal fayda üretmek, bu üretim sırasında da gerekli riskleri üstlenmek, yenilik yapmak ve üretim faktörlerini bir araya getirmektir (Aktaran: Ercan, 2017:23). Girişimcilik, girişimcinin elindeki fırsatları değerlendirerek bunu teşebbüse çevirme, bu teşebbüs ile kazancını arttırmayı hedefleme olgusudur. Günümüzde girişimcilik kavramı yeni iletişim teknolojilerinin gündelik yaşamın her alanını etkilemesiyle daha farklı bir boyuta ulaşmıştır. Özellikle, internet teknolojilerinin her alanda kullanılması, girişimciliğin de değişmesini sağlamıştır. Günümüzde internet aracılığıyla sadece ürün ve hizmet değil, enformasyon da pazarlanmaktadır. Web 2.0 teknolojilerinin sağladığı fırsatlar, enformasyon sunumunu ileri bir hale getirmiştir (Yıldırım ve Başer, 2016:172). Yeni girişimcilik modelinde ileri teknoloji, özellikle bilgi işlem ve iletişim teknolojilerinin kullanımı en önemli unsurdur. Dijital enstrümanları iş süreçlerinde verimli olacak şekilde kullanan girişimciler bilgi toplumuna dönüşümde önemli rol oynamaktadır (Koçak, 2010:386). Sosyal medya da günümüz girişimcileri açısından mal ve hizmetlerin satış ve pazarlanması faaliyetlerinde yaygın bir şekilde kullanılmaya başlamıştır. Özellikle sosyal medyanın iki yönlü iletişime izin veren yapısı yani interaktif olması bu ortamın hem bireyler hem de kuruluşlar için büyük fırsatlar sunmasını sağlamaktadır. Bireyler sosyal medya sayesinde sadece tüketici konumundan çıkıp hem üreten hem de tüketen bir konuma dönüşmüştür (Yeniçıktı, 2016:93). Bu araştırma üniversite öğrencilerinin sosyal medya ve girişimciliğe bakış açılarını ortaya koymak üzere hazırlanmıştır.

\section{VERI VE YÖNTEM}

\subsection{Araştırmanın Kapsamı, Önemi, Sınırılıkları}

Yapılan araştırmalar sonucunda, üniversite öğrencileri tarafından oldukça fazla kullanılan sosyal medya günümüz girişimcileri açısından mal ve hizmetlerin satış ve pazarlanması faaliyetlerinde yaygın bir şekilde kullanılmaya başlamıştır. Çalışma girişimcilik konusundaki güncel değişimleri ortaya koyma, daha önceden yapılan çalışmalara katkıda bulunma, daha sonra bu konuda yapılacak çalışmalara rehberlik etme ve sosyal medya girişimciliği alanında bilgi vererek mevcut uygulamaların geliştirilmesini sağlamak açısından önem arz etmektedir. Araştırmanın, sadece Selçuk Üniversitesi Beyşehir Ali Akkanat kampüsü işletme fakültesi, turizm fakültesi ve MYO'da okuyan öğrencilere uygulanması, Türkiye genelinde tüm üniversitelerin tamamına ulaşmanın güç olması, çalışmanın zaman ve maliyet kısıtları, verilerin anketi cevaplayan katılımcıların kişisel algılamalarına dayanması sebebiyle araştırma belirli sınırlılıkları taşımaktadır.

\subsection{Evren ve Örneklem}

Selçuk Üniversitesi Beyşehir Ali Akkanat kampüsü öğrencileri örneklemi oluşturmaktadırlar. Tüm kampüste işletme fakültesinde 627, turizm fakültesinde 300, Meslek Yüksek Okulunda 3461 olmak üzere toplam 4343 öğrenci vardır. 500 öğrenciye anket uygulaması yapılıp 390 geçerli anket araştırma için kullanılmıştır. 390 sayısının $\% 5$ güvenilirlik düzeyinde evreni temsil eden kabul edilebilir bir sayı olduğu tespit edilmiştir. 2016-2017 yılı Selçuk Üniversitesi Beyşehir Ali Akkanat kampüsünde öğrenim gören 390 İşletme Fakültesi, Turizm Fakültesi ve Meslek Yüksek Okulu öğrencisi araştırmanın örneklemidir. 


\subsection{Verilerin Toplanma Yöntemi ve Ölçekler}

Katılımcıların seçiminde kolayda örneklem yöntemi kullanılmıştır. Veri toplama aracı olarak öğrencilere yüz yüze anket uygulanmıştır. Anket iki bölümden oluşmaktadır. Anketin birinci bölümünde üniversite öğrencilerinin kişisel bilgilerine ulaşmak adına, yaş, cinsiyet, sosyal medya kullanımı ile ilgili bilgileri elde etmeye yönelik sorular yer almaktadır. Anketin ikinci bölümünde Leroy, Maes, Sels,Debrulle ve Meuleman tarafından uyarlanan Küçük (2014) tarafından yüksek lisans tezinde kullanılan güvenilirliği ölçülen (Cronbach's Alpha değeri 0.87) beşli likert tipi ölçek kullanılmıştır. Ölçekte girişimcilik, davranışa yönelik tutum, varsayılan davranış kontrolü ve kişisel norm olmak üzere üç boyutta ele alınmıştır.

\section{BULGULAR VE TARTIŞMA}

\subsection{Demografik Bulgular}

Katılımcıların \%48,2'si İşletme fakültesi, \%10,5'i Turizm fakültesi ve \%41,3'ü Meslek Yüksek okulu öğrencisidir. Öğrencilerin $\% 45,9^{\prime}$ u kız, \%54,1'i erkektir. Katılımcıların \%99,5'nin bir en az bir sosyal medya hesabı olduğu sonucuna ulaşılmıştır. Katılımcıların çoğunlukla \%37,4'ü günde ortalama 1-3 saat internette zaman harcamakta, \%49,7'si günde internette geçirdiği zamanın 1-3 saatini sosyal medya araçlarıyla geçirmektedir.

Tablo 1: Demografik Bulgular; Bölüm, Cinsiyet, Yaş, Hesap Bilgileri

\begin{tabular}{llrr} 
& & & \\
& & Frekans & Oran (\%) \\
\hline \multirow{2}{*}{ Bölüm } & İşletme Fakültesi & 188 & 48,2 \\
& Turizm Fakültesi & 41 & 10,5 \\
& MYO & 161 & 41,3 \\
\hline Cinsiyet & Erkek & 211 & 54,1 \\
& Kız & 179 & 45,9 \\
\hline Sosyal Medya Sitelerinde & Evet & 388 & 99,5 \\
hesabınız var mı? & Hayır & 2 & 0,5 \\
\hline & 1 saatten az & 22 & 5,6 \\
İnternette günde ortalama ne & $1-3$ saat & 145 & 37,4 \\
kadar zaman harcıyorsunuz? & $4-6$ saat & 142 & 36,6 \\
& 6 saat üzeri & 81 & 22,4 \\
\hline Internette geçirdiğiniz zamanın & 1 saatten az & 96 & 24,6 \\
ne kadarını Sosyal me & $1-3$ saat & 194 & 49,7 \\
dyada(Facebook, Twitter, & $4-6$ saat & 71 & 18,2 \\
Youtube vb.) geçiriyorsunuz? & 6 saat üzeri & 29 & 7,4 \\
TOPLAM & & 390 & $\% 100$ \\
\hline \hline
\end{tabular}

Tablo 2.2'de katılımcıların sosyal medya alışkanlıkları yüzdelerine baktığımızda, \%37,2'sinin arasıra fotoğraf paylaştığı, $\% 42,8^{\prime}$ inin sürekli sosyal medya sitelerinden gündemi takip ettiği, \%29,2'sinin arasıra arkadaşlarını veya akrabalarını sosyal medyada aramak için kullandığı, \%26,9'unun arasıra sosyal medyayı sohbet etmek amaçlı kullandığı, \%36,2'sinin nadiren yeni arkadaş bulmak için sosyal medyayı kullandığı, \% $29^{\prime}$ unun hiç dil geliştirmek için sosyal medyayı kullanmayı tercih etmediği, \%29'unun arasıra sosyal medyayı arkadaşlarının ne yaptığını kontrol etmek için kullandığı, \%43,6'sının hiç oyun için tercih etmediği, \%19'unun hiç kariyer fırsatlarını takip etmek için kullanmadığı gözlemlenmektedir. Geri kalan büyük kısmının kariyer fırsatları için takip ettiği sunucuna ulaşılmıştır. 


\section{Grafik 1: Üniversite Öğrencilerinin Sosyal Medya Kullanım Alışkanlığı Bilgileri-Fotoğraf ve Video Paylaşmak} Fotograf ve Video Paylaşmak

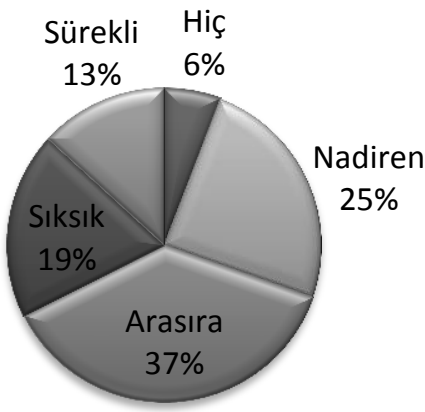

Selçuk Üniversitesi Beyşehir Ali Akkanat Kampüsünde öğrenim gören toplam 390 öğrencinin yüzde \%6'sı sosyal medyayı fotoğraf ve video paylaşmak için hiç kullanmamayı tercih ederken, \%25'i nadiren, \%37'si arasıra, \%19'u sıksık ve \%13'ü sürekli kullandığını belirtmiştir.

Grafik 2: Üniversite Öğrencilerinin Sosyal Medya Kullanım Alışkanlığı Bilgileri-Gündemi Takip Etmek

Gündemi Takip Etmek

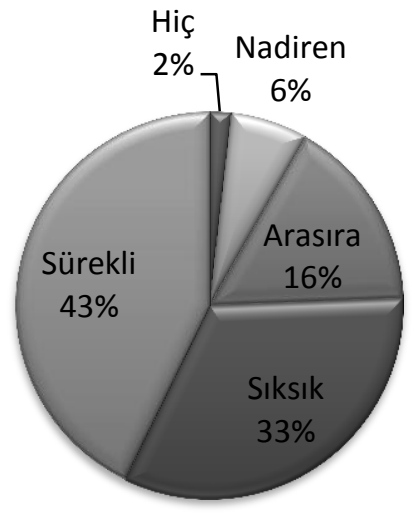

Selçuk Üniversitesi Beyşehir Ali Akkanat Kampüsünde öğrenim gören toplam 390 öğrencinin yüzde \%2'si sosyal medyayı gündemi takip etmek için hiç kullanmamayı tercih ederken, $\% 6^{\prime}$ sı nadiren, $\% 16$ 'sı arasıra, \%33'ü sıksık ve \%43'ü sürekli kullandığını belirtmiştir. 
Grafik 3: Üniversite Öğrencilerinin Sosyal Medya Kullanım Alışkanlığı Bilgileri-Kariyer-Girişimcilik Fırsatlarını Takip Etme

\section{Kariyer-Girişimcilik Fırsatlarını Takip Etme}

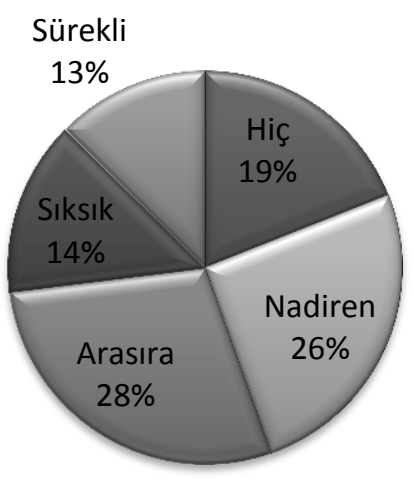

Selçuk Üniversitesi Beyşehir Ali Akkanat Kampüsünde öğrenim gören toplam 390 öğrencinin yüzde \%19’u sosyal medyayı kariyer fırsatlarını takip etmek için hiç kullanmamayı tercih ederken, \%26'sı nadiren, \%28'i arasıra, \%14'ü sıksık ve \%13'ü sürekli kullandığını belirtmiştir.

\section{Grafik 4: Sosyal Medya Araçlarının Kullanım Dağıımı}

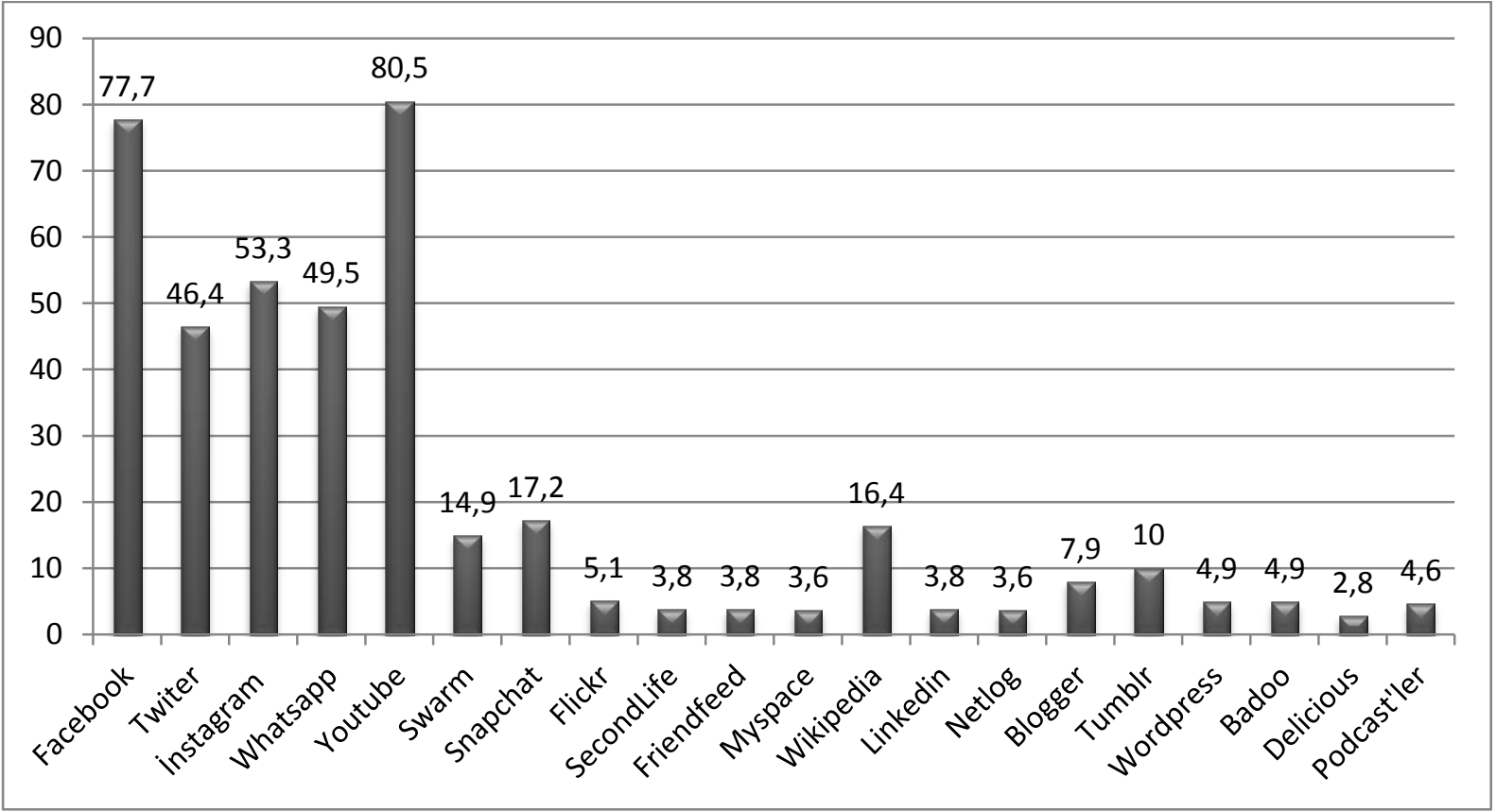

Katılımcıların sosyal medya araçlarının kullanım dağııımını gösteren Grafik 2.1'e göre katılımcıların \%80,5 ile en fazla sosyal medya aracı olarak Youtube kullanıcısı olduğu ardından sırayla \%77,7'sinin Facebook, \%53,3'ünün İnstagram, \%49,5'inin Whatsapp, \%46,4'ünün Twitter, \%17,2'sinin Snapchat ve \%16,4'ünün Wikipedia ve daha düşük yüzdeler ile diğer sosyal medya sitelerini kullandıkları görülmektedir. 


\subsubsection{Güvenilirlik Analizi}

Sosyal medya üzerinden girişimcilik sorularına verilen cevaplar sonucu yapılan güvenilirlik analizi sonucunda oluşan 30 ifadenin Cronbach's Alpha değeri \%93,6'dır. Bu da girişimcilik ölçeğinin oldukça güvenilir bir ölçek olduğunu bize göstermektedir.

\subsection{3.Öğrencilerin Sosyal Medya Üzerinden Girişimcilik Faaliyetlerine Bakış Açıları}

Öğrencilerinin davranışa yönelik tutumlarına ilişkin bulgular Tablo 2.2'deki gibidir. Buna göre en yüksek ortalamaya 4,14 ile "Iş ve özel hayat arasındaki dengenin önemli olduğunu düşünüyorum "dur. Öğrencilerinin davranışa yönelik tutumlarına ilişkin sorular arasında en düşük ortalamaya 3,41 ile "Girişimci birisi özel hayatı ve iş hayatının dengesini daha iyi kurar." olgusu almıştır. Bu durum öğrencilerin, girişimcilerin iş ve özel hayatlarını dengesinin önemli olduğuna yönelik bakış açıları olduğunu göstermektedir

Tablo 2: Davranışa Yönelik Tutuma ilişkin Bulgular

\begin{tabular}{|c|c|c|c|c|c|}
\hline & $\mathrm{N}$ & Minimum & Maximum & Mean & Std. Deviation \\
\hline \multicolumn{6}{|l|}{ Davranışa Yönelik Tutum } \\
\hline 1.illeride bir gün girişimci olmayı & 390 & 1 & 5 & 3,69 & 1,197 \\
\hline 2.Fırsatlar oluştuğunda girişimci & 390 & 1 & 5 & 3,78 & 1,080 \\
\hline 3.Girişimci olmak cazip görünüyor. & 390 & 1 & 5 & 3,74 & 1,089 \\
\hline $\begin{array}{l}\text { 4.Ilerıde bır gun gırışımcı olmayı } \\
\text { hayal ediyorum. }\end{array}$ & 390 & 1 & 5 & 3,63 & 1,157 \\
\hline $\begin{array}{l}\text { 5.Girişimcilerin kendi kendini } \\
\text { yönetme (otonomi)alanları } \\
\text { oldukça fazladır }\end{array}$ & 390 & 1 & 6 & 3,67 & 1,015 \\
\hline 6.Girişimciler iyi bir hayat sürerler. & 390 & 1 & 5 & 3,46 & ,989 \\
\hline $\begin{array}{l}\text { 1.Gırışıımı bırısı ozel hayatı ve ış } \\
\text { hayatının dengesini daha iyi kurar. }\end{array}$ & 390 & 1 & 5 & 3,41 & 1,086 \\
\hline $\begin{array}{l}\text { 8.Gelecekteki mesleğimde kendi } \\
\text { kendimi yönetmek isterim. }\end{array}$ & 390 & 1 & 5 & 4,04 & 1,033 \\
\hline $\begin{array}{l}\text { 9.Işimde karşılaşacağım } \\
\text { güçlüklerle uğraşabilirim }\end{array}$ & 390 & 1 & 5 & 3,96 & 1,007 \\
\hline $\begin{array}{l}\text { dengenin önemli olduğunu } \\
\text { düsünüyorum. }\end{array}$ & 390 & 1 & 5 & 4,14 & 1,027 \\
\hline
\end{tabular}

Öğrencilerinin varsayılan davranış kontrolüne ilişkin bulgular Tablo 2.3'deki gibidir. Ortalamalar incelendiğinde, ilk 4 olgunun 3 ve 4 arasında olduğu görülmektedir. Bu durum öğrencilerin bu soru kümesine çoğunlukla "kararsızım" ve "katılıyorum" cevaplarını verdiklerini göstermektedir. Öğrencilerinin büyük bölümü kendilerinde girişimci özelliği hissetmekte ve girişimci olmaları için gereken özelliklere sahip olduklarını göstermektedir. Girişimcilikle ilgili sorulardan son 4 olguya ise öğrenciler 34 arasında cevap vermişlerdir. Bu durum öğrencilerin genel olarak bu olgulara katıldıklarını göstermektedir. Öğrenciler yeni bir iş kurmanın finansal olarak çok fazla destek gerektiğine 4'e yakın bir cevap vermişlerdir. Girişimcilik için gerekli devlet desteği yoktur sorusuna ise yine 4'e yakın yani katılıyoruma yakın bir cevap vermişlerdir.

Tablo 3: Varsayılan Davranış Kontrolü

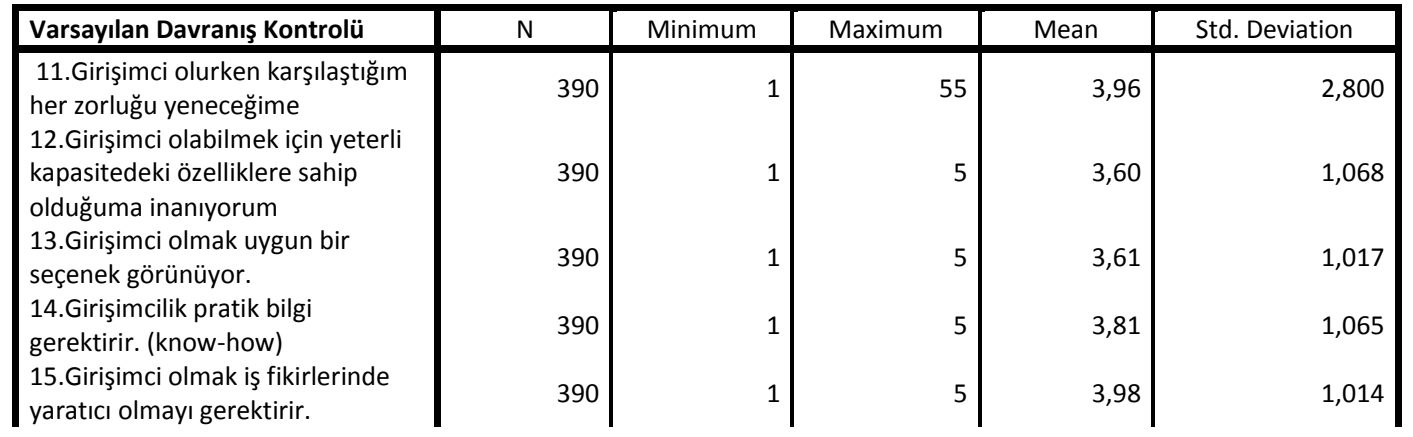




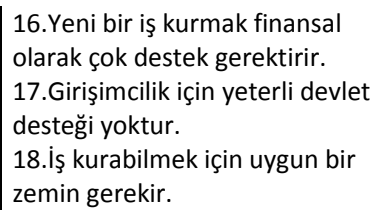

18. İş kurabilmek için uygun bir zemin gerekir.
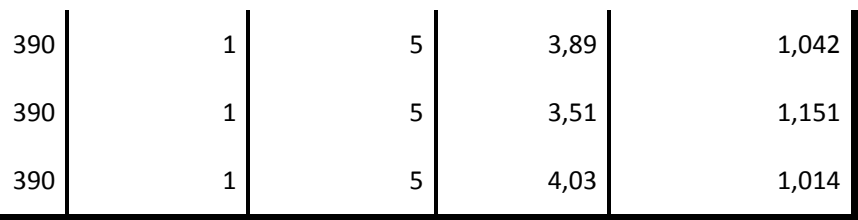

Öğrencilerinin kişisel normlarına ilişkin bulgular Tablo 2.4'deki gibidir. Kişisel norm olgularına ilişkin ortalamalar incelendiğinde, tüm değerlerin 3 ve 3,76 arasında olduğu görülmektedir. Bu durum öğrencilerin bu soru kümesine çoğunlukla "kararsızım" ve "katılıyorum" cevaplarını verdiklerini göstermektedir. Öğrencilerinin büyük bölümü kendilerinde girişimci özelliği hissettiğine katılmakta ve girişimci olmaları için gereken özelliklere sahip olduklarını ifade etmişlerdir.

\section{Tablo 4: Kişisel Norm}

\begin{tabular}{|c|c|c|c|c|c|}
\hline Kişisel Norm & $\mathrm{N}$ & Minimum & Maximum & Mean & Std. Deviation \\
\hline 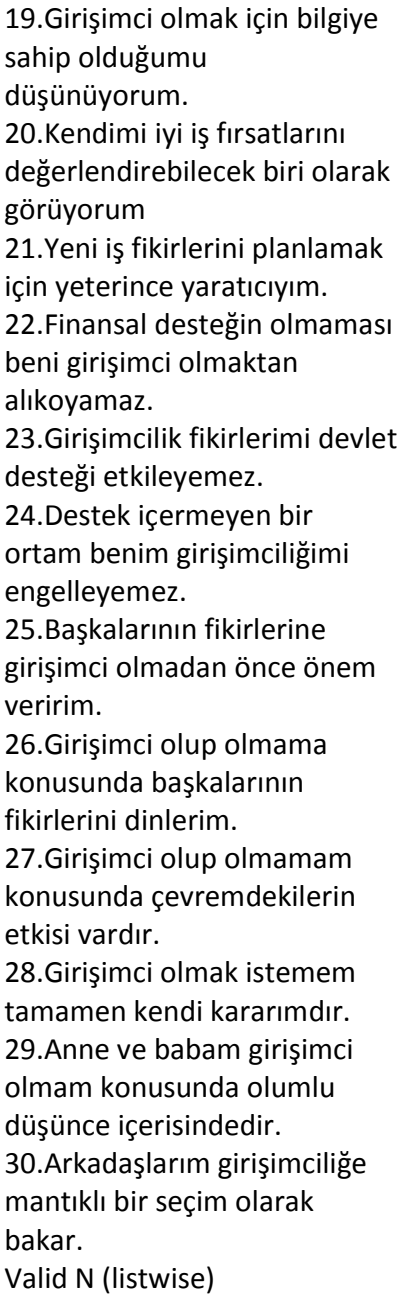 & $\begin{array}{l}390 \\
390 \\
390 \\
390 \\
390\end{array}$ & 1 & 5 & $\begin{array}{l}3,73 \\
3,59 \\
3,35 \\
3,29 \\
3,45 \\
3,62 \\
3,65 \\
3,44 \\
3,76 \\
3,68\end{array}$ & $\begin{array}{l}1,080 \\
1,012 \\
1,042 \\
1,198 \\
1,173 \\
1,170 \\
1,074 \\
1,089 \\
1,165 \\
1,071 \\
1,049 \\
1,085\end{array}$ \\
\hline
\end{tabular}

\section{SONUÇ}

Hayatımızdaki önemi hergeçen gün biraz daha artan sosyal medya, yaşantımızı farklılıklara uğrattığı gibi ticarette de birçok faaliyetin farklılaşmasına neden olmaktadır. Yapılan anket sonuçları göstermektedir ki üniversite öğrencilerinin neredeyse tamamına yakını sosyal medyayı kullanmaktadır. Büyük çoğunluğu her gün sosyal medyaya girmektedir. Katıımcıların \%80,5 ile en fazla sosyal medya aracı olarak Youtube kullanıcısı olduğu ardından sırayla \%77,7'sinin Facebook, \%53,3'ünün 
İnstagram, \%49,5'inin Whatsapp, \%46,4'ünün Twitter, \%17,2'sinin Snapchat ve \%16,4'ünün Wikipedia ve daha düşük yüzdeler ile diğer sosyal medya sitelerini kullandıkları görülmektedir. Selçuk Üniversitesi Beyşehir Ali Akkanat Kampüsünde öğrenim gören toplam 390 öğrencinin yüzde \%19'u sosyal medyayı kariyer/girişim fırsatlarını takip etmek için hiç kullanmamayı tercih ederken, \%26'sı nadiren, \%28'i arasıra, \%14'ü sıksık ve \%13'ü sürekli kullandığını belirtmiştir. Yani büyük bir kısmı sosyal medyadan kariyer/girşimcilik faaliyetlerini takip etmektedir. Girişimcilik, davranışa yönelik tutum, varsayılan davranış kontrolü ve kişisel norm olmak üzere üç boyutta ele alınmıştır. Üç boyutta da öğrencilerin girişimciliğe önem verdiği sonuçlarına ulaşıımıştır. Sosyal medyanın gittikçe önem kazandığı günümüzde girişimcilik faaliyetlerini sosyal medyadan yürütmeye ılımlı gençlerin olması girişimciliğin gelecekte alacağı hal açısından önem taşımaktadır. Eğitimciler, öğrencilerin her gün kullandıkları ve çok fazla zaman harcadıkları sosyal medya ağlarının eğitimde etkili kullanımı sağlayarak, internet okur yazarlığı eğitimleri verilerek, gençlerin bu ağları sık kullanımlarının yanında etkili ve faydalı amaçlar için kullanabilmelerini sağlanmalı ve gelecekteki kariyer durumları acısından bir fırsata dönüştürebilmelerine destek olunması tavsiye edilebilir.

\section{KAYNAKLAR}

Çelik, A., Akgemci, T., (2010), Girişimcilik Kültürü ve Kobiler, Geliştirilmiş 3. Baskı, Gazi Kitabevi, Konya.

Ercan, S., (2017), Duygusal Zekâ İle Girişimcilik Arasındaki İlişki: Karabük Üniversitesi Girişimcilik Bölümü Öğrencileri Örneği, Karabük Üniversitesi, Sosyal Bilimler Enstitüsü, İşletmeAnabilim Dalı, Yüksek Lisans Tezi, Karabük

Karaca, M., (2015), Girişimciliği Belirleyen Kişilik Özellikleri, Erciyes Üniversitesi, Sosyal Bilimler Enstitüsü, İşletme Anabilim dalı, Doktora Tezi, Kayseri.

Koçak, O., (2009), Bilgi Teknolojilerini Kullanan Yeni Girişimcilik Modelinin İş Yaratma Etkisi, Sosyal Siyaset Konferansları, İstanbul Üniversitesi İktisat Fakültesi Yayınları, 57, 381-405.

Küçük, K. A., (2014), Kişilik Özelliklerinin Girişimcilik Davranışına Etkisi; “Abant İzzet Baysal Üniversitesi” Örneği, Türk Hava Kurumu Üniversitesi, Sosyal Bilimler Enstitüsü, Yüksek Lisans Tezi.

Ural A. , Kılıç İ., (2006). Bilimsel Araştırma Süreci ve SPSS ile Veri Analizi.(2.Baskı).Ankara : Detay Anatolia Akademik Yayıncılık Ltd. Şti.

Yeniçıktı, N. T., (2016), Halkla İlişkiler Aracı Olarak Instagram: Sosyal Medya Kullanan 50 Şirket Üzerine Bir Araştırma, Selçuk İletişim, 9,2, 92115.

Yıldırım, O., Başer, E., (2016), İnternetin Girişimciliği Kapsamında Değişen Enformasyon Siteleri Üzerine Bir Değerlendirme, Global Media Journal TR Edition, 6 ,12, 172-200. 